\title{
REVIEW
}

\section{Acute Lung Injury: Clinical Concept and Experimental Approaches to Pathogenesis}

\author{
Minoru Kanazawa \\ Department of Medicine, School of Medicine, Keio University, Tokyo, Japan
}

(Received for publication on January 27, 1996)

\begin{abstract}
Acute lung injury (ALI) was defined recently as a syndrome of inflammation and increased permeability of the lungs that is associated with clinical, radiologic, and physiologic abnormalities that can not be explained by left atrial hypertension. ALI has the same clinical spectrum, although in a milder form, as acute respiratory distress syndrome (ARDS). The risk factors, incidence, and prognosis of ALI are described based on the medical literature and data collected at Keio University Hospital. We estimate that 20,000 to 40,000 cases of ALI, half of which also have ARDS, occur annually in Japan. Despite the new diagnostic criteria, the clinical entity of ALI remains to be clarified both physiologically and biochemically because of the lack of direct diagnostic methods. I briefly review the central mediator(s) and their role in the inflammatory cascade of ALI. Experimental studies and pharmacological interventions from our laboratory are also described. (Keio J Med 45 (3): 131-139, September 1996)
\end{abstract}

Key words: acute lung injury, acute respiratory distress syndrome, neutrophil, macrophage, priming

\section{Introduction}

The term "acute lung injury (ALI)" has been used mainly in the research arena to refer to an acute change in function and structure of the lungs, leading to hypoxemia and permeability edema of nonspecific etiologies. The term covers many experimental lung conditions induced by a variety of stimuli, such as bacterial lipopolysaccharide, cytokines, and other tissue damaging substances. ALI is now accepted as a general term to represent a disease process clinically observed in the lungs of patients with acute respiratory distress syndrome (ARDS). ${ }^{1}$ The European - American Consensus Conference on ARDS in 1994 defined ALI as a clinical syndrome which shares the pathophysiology of ARDS. ${ }^{2}$ The Conference concluded that much more needs to be investigated about the mechanisms and treatments of this fatal disorder, although an enormous amount of knowledge about ALI and ARDS has been accumulated from both clinical and experimental works, during the 25 years since Ashbaugh and colleagues formulated the original definition of ARDS. ${ }^{3}$ In the first part of this review, I describe the current concept, risk factors, incidence and prognosis of ALI. I then describe the pathophysiology and pathogenesis of ALI based mainly on the observation of patients with ALI at Keio University Hospital and the results of our experimental studies.

\section{Clinical Concept}

\section{Definition of ALI and ARDS}

The basic concept of ARDS is still based on Ashbaugh's criteria; 1) an appropriate risk factor, 2) acute onset, 3) refractory hypoxemia, 4) loss of lung compliance, 5) diffuse infiltration on chest $X$-ray, 6) previously normal lungs, and 7) no evidence of heart failure. ${ }^{3}$ These signs and symptoms are believed to be due to changes in permeability of the pulmonary microvasculature where major insults occur. The post-mortem finding is nonspecific diffuse alveolar damage, featuring alveolar edema, cellular infiltration and the presence of hyaline membrane formation. The Consensus Conference ${ }^{2}$ defined ALI and ARDS as syndromes of inflammation and increased permeability associated with a constellation of clinical, radiologic, and physiologic abnormalities that 
Table 1 Criteria for Acutc Lung Injury (ALI) and Acute Respiratory Distress Syndrome (ARDS) ${ }^{2}$

\begin{tabular}{|c|c|c|c|c|}
\hline & Timing & Oxygenation & Chest Radiograph & $\begin{array}{l}\text { Pulmonary Artery } \\
\text { Wedge Pressure }\end{array}$ \\
\hline ALI Criteria & Acute onset & $\begin{array}{l}\mathrm{Pa}_{\mathrm{O} 2} / \mathrm{F}_{1 \mathrm{O} 2} \leqslant 300 \mathrm{~mm} \mathrm{Hg} \\
\text { (regardless of PEEP } \\
\text { level) }\end{array}$ & $\begin{array}{l}\text { Bilateral } \\
\text { infiltrates seen on } \\
\text { frontal chest } \\
\text { radiograph }\end{array}$ & $\begin{array}{l}\leqslant 18 \mathrm{~mm} \mathrm{Hg} \text { when } \\
\text { measured or no } \\
\text { clinical evidence } \\
\text { of left atrial } \\
\text { hypertension }\end{array}$ \\
\hline ARDS Criteria & Acute onset & $\begin{array}{l}\mathrm{Pa}_{\mathrm{O}_{2}} / \mathrm{F}_{\mathrm{IO} 2} \leqslant 200 \mathrm{~mm} \mathrm{Hg} \\
\text { (regardless of PEEP } \\
\text { level) }\end{array}$ & $\begin{array}{l}\text { Bilateral } \\
\text { infiltrates seen on } \\
\text { frontal chest } \\
\text { radiograph }\end{array}$ & $\begin{array}{l}\leqslant 18 \mathrm{~mm} \mathrm{Hg} \text { when } \\
\text { measured or no } \\
\text { clinical evidence } \\
\text { of left atrial } \\
\text { hypertension }\end{array}$ \\
\hline
\end{tabular}

cannot be explained by, but may coexist with, left atrial or pulmonary capillary hypertension. The clinical criteria for ALI and ARDS are shown in Table 1, indicating that the only difference between ALI and ARDS is the cutoff value of $\mathrm{Pa}_{\mathrm{O}_{2}} / \mathrm{F}_{\mathrm{IO}}$. In other words, ARDS represents a severe condition of ALI, and both are considered to include the same spectrum of clinical signs.

\section{Risk factors}

Many diseases and clinical situations are considered to be risk factors for ALI. Risk factors that cause direct injury to the lungs are gastric aspiration, toxic gas inhalation, fat embolism syndrome, near-drowning, lung contusion, and diffuse pulmonary infections such as influenza pneumonia, pneumocystis carinii pneumonia, and miliary tuberculosis. Risk factors for indirect injury to the lungs are sepsis syndrome, shock, multiple trauma, burn, acute pancreatitis, disseminated intravascular coagulation, hypertransfusion, as well as cardiopulmonary bypass and upper abdominal surgery. The systemic inflammatory response syndrome (SIRS) is a recently proposed clinical syndrome describing the biologic responses to infection and other inflammatory insults. ${ }^{4}$ Although a clinical progression from SIRS to ALI and ARDS can be suspected, the reported incidence of ARDS among the patients with SIRS remains $2-6 \% .^{5}$ The incidence of ARDS among patients with sepsis syndrome ranges 25$42 \% .^{2}$ It seems that the criteria for SIRS were so liberal as to include a large number of patients who would be at significant risk for ARDS.

Table 2 shows the risk factors in 64 patients with ALI and ARDS at Keio University Hospital from January 1990 to March $1995 .^{6-8}$ In our series, septic syndrome was the most common risk factor and the leading cause of death in patients with ALI and ARDS, as indicated by others reported. ${ }^{9}$ The abdomen was usually the source when sepsis syndrome preceded the ARDS, but there was usually a pulmonary source when sepsis syndrome oc-
Table 2 Risk Factors in 64 Patients with ALI/ARDS at Keio University Hospital from January 1990 to March 1995 (4-6)

\begin{tabular}{lcc}
\hline \hline & Number of Patients & Percent \\
\hline Sepsis/Sepsis Syndrome & 17 & $26.6 \%$ \\
Pneumonia & 13 & $20.3 \%$ \\
Unknown & 10 & $15.6 \%$ \\
Gastric Aspiration & 4 & $6.3 \%$ \\
Cerebrovascular Accident & 4 & $6.3 \%$ \\
Drug Induced & 4 & $6.3 \%$ \\
Post Surgery & 3 & $4.7 \%$ \\
Trauma & 2 & $3.1 \%$ \\
Reexpansion of Pneumothorax & 2 & $3.1 \%$ \\
Others & 5 & $7.8 \%$ \\
\hline Total & 64 & $100.0 \%$ \\
\hline
\end{tabular}

curred after the onset of ARDS. ${ }^{9}$ Our experience also suggested that pulmonary infection was both an important risk factor and a late complication of ALI. ${ }^{6}$ Other risk factors noted in our institution were gastric aspiration, neurogenic pulmonary edema induced by cerebrovascular accident, and ALI induced by drugs. A significant number of cases (10 cases, $15.6 \%)$ had undetermined etiologies in our series, but some were suspected to be pulmonary infections with unknown causative agents.

\section{Incidence}

The exact incidence of either ALI or ARDS is unknown. The figures for ALI would be greater than those for ARDS, because ALI includes ARDS in its severe form. To date, no data indicating the relative incidence of ALI as compared with that of ARDS. In the United States, the National Heart and Lung Institute estimated that up to 150,000 cases of ARDS occur annually. ${ }^{10}$ Extrapolation of the US data to Japan suggests approximately $60,000-80,000$ cases of ARDS occur each year, 
although there are no data to support these figures. The incidence reported in the US has been challenged, and it may be an overestimation. ${ }^{11,12}$ In the United Kingdom, for example, annual incidence predicted was to be 0.05 / 1000 , where as the incidence in the US would correspond to $0.6 / 1000 .^{12}$ The differences in the reported incidence of ARDS reflect the various criteria used for making the diagnosis. Based on the Consensus Conference criteria, ${ }^{2}$ we found 43 patients with ARDS seen at Keio University Hospital from April 1992 to March 1995. From this survey we roughly estimated the annual incidence of ARDS in Japan to be $10,000-20,000$ cases; this figure agreed with the estimates from a symposium on ALI held at the annual conference of Japan Society of Chest Diseases. ${ }^{4}$ The symposium also agreed that the incidence of ALI might be about 20,000 to 40,000 cases a year in Japan.

\section{Prognosis}

The fatality rate associated with ARDS has remained generally $50-60 \%$ since the original report in 1967 . The fatality rates are even higher in patients over age 60 years, those with sepsis syndrome, and those with multiple organ failure. ${ }^{13}$ The published fatality rates of ARDS, however, differ from $10 \%$ in patients with fat embolism to $90 \%$ with sepsis syndrome. Again, variation among these figures is due to the heterogeneity of underlying diseases, lack of generally accepted criteria for ARDS, and the wide variability in the mode of therapy. The fatality rate was $56 \%$ in our series of 64 patients with ARDS induced by various risk factors (Table 2). Recently, Milberg et $\mathbf{l}^{14}$ reported a significant decrease in fatality rates from $50 \%$ in 1990 to $36 \%$ in 1993 in 918 patients with ARDS, while the fatality rates remained unchanged at around $60 \%$ from 1983 to 1989 . Even in sepsis patients, who comprised $37 \%$ of the subjects, the fatality rates declined steadily from $67 \%$ in 1990 to $40 \%$ in 1993. The decrease in the fatality rates occurred largely in patients younger than age 60 years and in those with sepsis syndrome at risk for ARDS. The extent to which experimental therapies or other changes in treatment contributed to the decline in the fatality rates could not be determined. As for the fatality rate of ALI, no data has yet been determined.

\section{Clinical Studies}

\section{Physiological diagnosis}

ALI is defined as a syndrome of inflammation and increased permeability of the lungs, ${ }^{2}$ and there is a consensus that ALI is a form of permeability pulmonary edema. It is believed that measurements of extravascular lung water and permeability are necessary both for assess- ing the alveolar septal injury and for making a direct and quantitative diagnosis of permeability edema. Measurements that are clinically feasible, however, have not yet become available. All the clinical criteria used so far, including the Consensus Conference criteria, are more or less irrelevant because of the lack of straightforward diagnostic methods.

The measurement of extravascular lung water has limited clinical application, because it has recently become clear that the measurement, although it may be accurate and reproducible, is rather insensitive for the early detection of acute lung injury. ${ }^{15}$ Many methods have been introduced. Some were theoretically sound, but none are actually used. ${ }^{16}$ An important example is the thermodilution measurement of lung water content, which has been relegated to a minor role, except in some research projects. The method currently used is chest $x$-ray, which is simple and noninvasive but not quantitative.

There is a need to develop to measure the change in solute flux across the alveolar-capillary barrier so that permeability can be assessed. Since the alveolar-capillary septum consists of both epithelial and endothelial membranes, different methods have been developed to assess these barrier functions. ${ }^{17}$ One approach is to estimate epithelial leakage using ${ }^{99 \mathrm{~m}} \mathrm{Tc}$-labeled diethylenetriamine pentaacetate (DTPA) administered as an aerosol via the airway. The clearance of this small water-soluble molecule (492 Da) from the lungs is observed externally using a gamma camera, and the clearance rate is calculated. The clearance rate is determined by the slow passage through the tight epithelial intercellular junctions in the alveoli and peripheral airways. ${ }^{18}$ The clearance rate is, therefore, believed to represent epithelial permeability; this hypothesis is widely accepted. ${ }^{19}$ The test is simple, and the whole procedure takes only $15-20 \mathrm{~min}$. The method is highly sensitive to mild lung injury, such as smoking, ${ }^{18}$ and even to physiological changes in lung volume ${ }^{20} \mathrm{We}$ also observed the increases in ${ }^{99 \mathrm{~m}} \mathrm{Tc}$ DTPA clearance in moderate injury of patients with interstitial lung diseases. ${ }^{21}$ The high sensitivity, however, might obscure the degree of lung injury; for example, healthy smokers and patients with ARDS showed similar clearance values..$^{22}$ If the high sensitivity was due to the size of the tracer molecule and if a tracer with adequate molecular size could be used, then the severer injury could be differentiated from the mild one. ${ }^{23}$

Another approach to assessing the alveolar-capillary function is to estimate endothelial permeability using the tracer protein equilibration method which estimates the rate of tracer protein accumulation in the lung tissue across microvascular endothelium from plasma. ${ }^{17}$ Radioisotopic albumin or transferrin is administered intravenously, and external gamma counting over the chest makes it possible to analyze changes in pulmonary microvascular permeability. ${ }^{6,24}$ Figure 1 shows the endothelial 


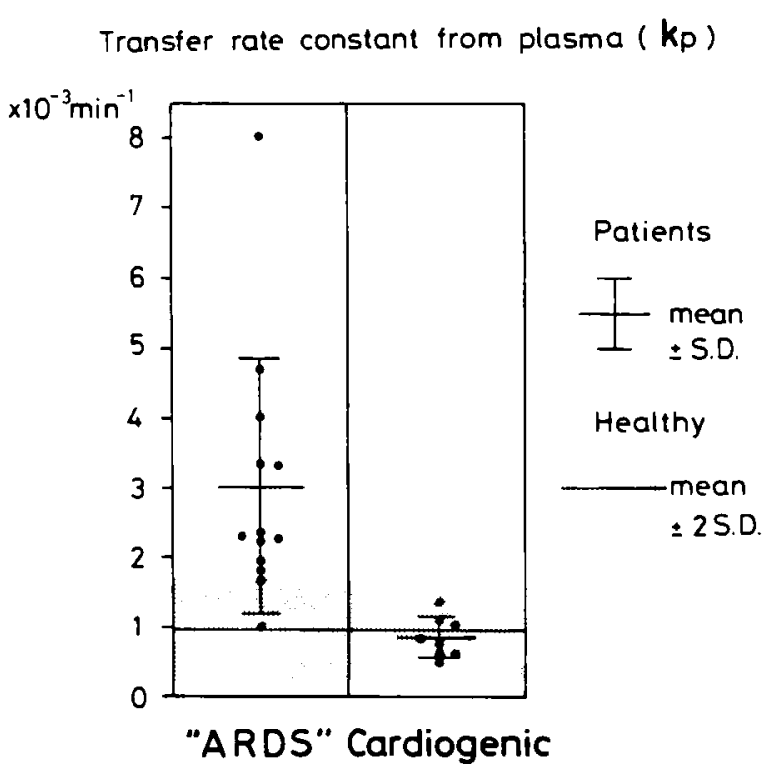

Fig 1 The transfer rate constant $\left(\mathrm{kp} ; \times 10^{-3} / \mathrm{min}\right)$ from plasma to lung tissue for Tc-99m human serum albumin. The methods enable the differentiation of increased microvascular permeability in patients with ARDS and cardiogenic pulmonary edema.

permeability represented as the transfer rate constant (\% of mass flux per time) observed in patients with ARDS and cardiogenic pulmonary edema. The data clearly differentiated the two types of pulmonary edema. This method is noninvasive and sensitive, providing regional information. There is concern about repeatability, errors caused by radioisotope-tracer dissociation and patient movement, the assumption of vascular volume during the measurement, and corrections for gammaray absorption by the chest walls. ${ }^{15}$ In addition, one of the problems with this method is that a patient, although intubated and even mechanically-ventilated, must be transferred to an area where the use of a radioisotope is permitted under current Japanese regulations.

A clinical test should be developed to directly measure the change in permeability or cellular injury. The test would then define the clinical spectrum of ALI more clearly, and help to diagnose patients earlier when they are at risk of developing ALI.

\section{Biochemical diagnosis}

At the onset of ALI, various mediators are released into the lungs and some leak into the peripheral circulation. Figure 2 shows acute changes in mediator concentration in pulmonary edema fluid as seen in a patient with re-expansion pulmonary edema who was observed chronologically from the onset of the disease. ${ }^{25}$ Interleukin-8 (IL-8) and leukotriene B4 (LTB4) concentrations in

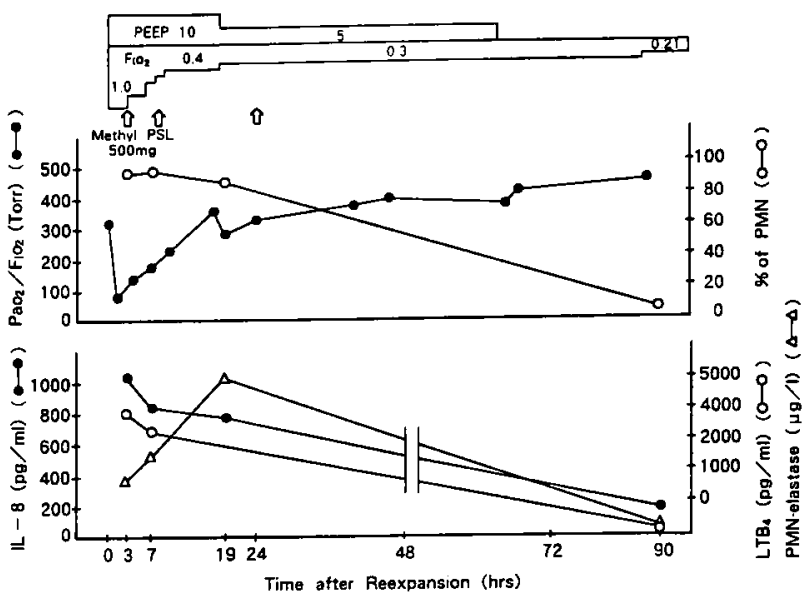

Fig 2 The time course of mediators observed in a patient with reexpansion pulmonary edema. $\mathrm{A} \mathrm{Pa}{ }_{\mathrm{O} 2} / \mathrm{F}_{\mathrm{IO} 2}$ and $\% \mathrm{PMN}$ in $\mathrm{BALF}$ (the upper graph) and the concentrations of IL-8, LTB4, and PMN elastase in BALF (the lower graph) are shown. The levels of IL-8 and LTB4 were elevated immediately after the reexpansion; then the PMN elastase level increased transiently and the $\mathrm{Pa}{ }_{\mathrm{O}_{2}} / \mathrm{F}_{\mathrm{IO} 2}$ and $\% \mathrm{PMN}$ in BALF recovered.

edema fluid were increased in the very early phase of lung injury, and polymorphonuclear (PMN) elastase concentration subsequently increased. These increases subsided and the chest $\mathrm{x}$-ray infiltration disappeared within 4 days. The changes also paralleled the increase in the number of PMNs in edema fluid and the degree of hypoxemia. Likewise the plasma concentrations of IL-8, PMN elastase, and the soluble form of P-selectin were elevated during the acute phase. These data suggest that the measurement of these mediators in bronchoalveolar lavage fluid (BALF) or peripheral blood may be a useful indicator of ALI.

In 1980, Hammerschmidt and co-workers ${ }^{26}$ reported that the presence of a leukocyte aggregant, C5a, in plasma predicted the subsequent onset of ARDS. They hypothesized that all risk factors, such as endotoxemia, trauma, and pancreatitis, for ARDS have the ability to activate intravascular complement which could induce intrapulmonary neutrophil aggregation and neutrophilmediated lung injury, resulting in ARDS. This hypothesis seemed to establish the definitive mechanisms of ARDS and to identify subjects who need therapeutic intervention early in the course of the disease. Studies conducted to confirm this hypothesis failed to do so. Weinberg et $a l^{27}$ found that complement activation is nonspecific in patients with sepsis syndrome and has no predictive value either at the onset or during the subsequent progression of ARDS. The reason for the discrepancy between these studies is not clear, but more recent studies are being conducted at more appropriate study settings and measure- 
ments of C5a are more sensitive. Now it can be concluded that the complement component has no reliable predictive value for recognizing patients with ARDS. ${ }^{28}$

Currently, there is no single marker, whether biochemical or physiological, to predict the onset, severity or outcome of ALI. However, it is possible that some marker may have predictive value in specific clinical settings. Fujishima et $a l^{29}$ found a positive correlation between the measured IL- 8 concentration in BALF and the degree of hypoxemia in 7 patients with possible inhalation injury, suggesting that BALF IL-8 concentration may predict lung injury. We also observed a case with ARDS in which BALF IL-8 concentrations were correlated with lung PMN accumulation and degree of lung injury. ${ }^{30}$ IL-8 concentrations in pulmonary edema fluid was also elevated in a patient with re-expansion pulmonary edema as mentioned above (Fig 2).

When measuring the concentration of a mediator in BALF, it may be reasonable to show the high predictive value of a particular mediator by sampling from the center spot of inflammation. However, conducting bronchofiber scopy in critically ill patients with ALI is always risky and difficult. Therefore, we explored the significance of blood biochemical mediators in 21 patients with ALI, ${ }^{4.5}$ by measuring PMN myeloperoxidase as a marker for neutrophil activation, thiobarbituric acid reactive material (TBARM) for lipid peroxidation of endothelial cell membrane, ${ }^{31} 7 \mathrm{~S}$ collagen for basement membrane damage, ${ }^{32}$ and the soluble form of P-selectin ${ }^{33}$ for the adhesive interaction between inflammatory cells and vascular endothelium. Plasma concentrations of TBARM, $7 \mathrm{~S}$ collagen, and P-selectin were elevated, correlating with acute lung injury score as proposed by Murray et al. ${ }^{1}$ As compared with patients who survived, those who were deceased had elevated levels of markers. For example, all plasma levels of P-selectin in the deceased patients were higher than those in the control group, indicating possible potential for the differentiation. As compared with ALI patients without complicated multiple organ failure (MOF), those with complicated MOF had elevated plasma concentration of $7 \mathrm{~S}$. The data suggest that plasma $7 \mathrm{~S}$ collagen might be a specific indicator of pulmonary microvascular injury in ALI patients while they complicated systemic vascular damage in MOF. Needless to say, these findings should be confirmed in larger clinical studies.

\section{Experimental Studies}

\section{Neutrophils}

The currently accepted hypothesis regarding the pathogenesis of ALI is that various insults either activate the complement system or stimulate mononuclear phagocytes to release cytokines and other mediators, causing an abnormal accumulation of neutrophils and other inflammatory cells in the lungs; these cells subsequently release damaging products, such as oxygen radicals and proteinases, resulting in ALI. ${ }^{34-36}$ Much emphasis has been placed on the role of neutrophils in the etiology of ALI, as evidenced in both human and animal studies. Numerous data have been obtained from intact animals, isolated perfused animal lungs, and cultured lung cells.

The classic approach for proving the neutrophil dependence of lung injury is to deplete the animal of circulating neutrophils and observe the attenuation of ALI that occurs following administration of damaging stimuli. ${ }^{37}$ The neutrophil depletion, however, does not always reduce lung injury. ${ }^{38}$ The outcome is dependent on the types and routes of administration of stimuli in our experimental model of guinea pigs. As compared with control animals, neutrophil depleted guinea pigs had the attenuated lung injury after treatment with Escherichia coli (E. coli) endotoxin (lipopolysaccharide: LPS) ${ }^{39}$ The lung injury was not attenuated when live $E$. coli was given intravenously (i.v.). ${ }^{40}$ When we administered LPS via the airways, neutropenia did not have a significant attenuation effect on the injury. ${ }^{41}$ Furthermore, when we administered live Pseudomonas aeruginosa ( $P$. aeruginosa) intratracheally (i.t.) to neurotropenic animals, we found that the responses were exacerbated implying that neutrophils are necessary to defend lungs from bacterial infection. This data suggests that neutrophils sometimes play a major role in producing ALI, but lung injury without neutrophils could be even more serious when challenged by live bacteria. ${ }^{42}$

In these experiments, we modulated neutrophil number and function by pretreating animals with recombinant granulocyte colony-stimulating factor (rG-CSF). Again, the responses to LPS differed based on the route of administration of stimuli. In the rG-CSF pretreated animals, the injury was unexpectedly attenuated when LPS was given i.v. ${ }^{39}$ although the number of circulating neutrophils was markedly increased. On the other hand, the injury was exacerbated during i.t. LPS. ${ }^{41}$ The mechanisms of weakened response to i.v. LPS is unclear, but we found that neutrophils pretreated with rG-CSF were less adhesive to lung vasculature after i.v. LPS in vivo ${ }^{39}$ and that human neutrophils activated by rG-CSF suppressed tumor necrosis factor (TNF)-release from monocytes stimulated by LPS in vitro. ${ }^{43}$ This data could mean that modulating neutrophil function is a possible method for controlling ALI, although practical approaches have yet to be investigated. In addition, the lung responses to live $P$. aeruginosa were different depending on the amount of the bacterial ceils instilled i.t. in neutrophilic animals. When the amount was small $\left(10^{4}\right.$ colony forming unit [CFU]), the lung injury did not occur while a large amount $\left(10^{8} \mathrm{CFU}\right)$ exacerbated the lung injury. ${ }^{42}$ The results showed that a normal or increased number of 
neutrophils in peripheral circulation may be protective when infectious stimulus is mild, but excess neutrophils could be destructive when the stimulus is strong. It seems that neutrophils serve the key inflammatory role in both the defense against invading bacteria and the development of ALI.

\section{Mononuclear phagocytes}

The potential role for neutrophils and the resulting products in the pathogenesis of ALI has been welldocumented. ${ }^{28,35,36,38}$ On the other hand, ALI occurs in patients with severe neutropenia without pulmonary neutrophil infiltration. ${ }^{44}$ The cause of ALI in these cases is unknown, but multiple humoral and cellular mechanisms may contribute to the onset. Among the cells involved in ALI, macrophages in the pulmonary interstitium and alveolar spaces possess the same potentials for damage as neutrophils. ${ }^{45}$ They contain a variety of enzymes and can release oxygen metabolites. In addition, they can absorb enzymes released by other inflammatory cells such as PMN elastase and later release them at inflammatory sites. ${ }^{46}$ Macrophages have been implicated in the process of damage associated with many acute and chronic lung diseases, ${ }^{45}$ and could be the cause of ALI in the absence of neutrophils.

In addition to their role in the mechanism directly causing ALI, macrophages and other mononuclear phagocytes can participate in the development of ALI indirectly by releasing mediators in both the lungs and the peripheral circulation. For example, alveolar macrophages are the first cells to be activated by inflammatory stimuli to secrete cytokines like IL-1 $\beta$ and TNF $\alpha$ in aspiration pneumonia. Activated macrophages may injure the lung tissue directly in the area where the stimulus is added, but they can release these cytokines in the peripheral circulation to augment systemic cellular and humoral inflammatory responses, resulting in neutrophil accumulation in the lungs and extensive lung injury. ${ }^{47-49}$ Even when the insult occurs indirectly to the lungs as with sepsis syndrome, intravascular mononuclear phagocytes might play a significant role by triggering the inflammatory cascade. We observed augmented lung injury induced by LPS when cells in the reticuloendothelial system were activated by phagocytozing latex particles. ${ }^{50}$ This data suggests that both alveolar macrophages and intravascular mononuclear phagocytes are important for generating lung inflammatory responses to the stimuli.

Priming leukocytes follows exposure of the cells to one stimulus even at very low doses, and enhancing of leukocyte function follows exposure to a second stimuli. Thus, priming macrophages can be another important mechanism for enhancing inflammatory injury mediated by neutrophils in many lung diseases. We found that alveolar macrophages are primed for IL-8 production in patients with idiopathic pulmonary fibrosis. ${ }^{51}$ Both pulmonary macrophages and intravascular mononuclear phagocytes could be primed in the setting of ALI. The first stimuli could be LPS, C5a, N-formylated peptides (FMLP), or platelet activating factor (PAF). All of these are detectable in both clinical and experimental lung injuries. The enhanced functions include generation of $\mathrm{O}_{2}$; adhesion of cells; release of lysosomal enzymes, arachidonate metabolites and PAF; phagocytic and bactericidal capacities; and injury to target cells. Most, but not all, of these secondary responses are neutrophildependent. ${ }^{52}$ We primed leukocytes by Bacillus Calmette Guerin (BCG) at 10 days before the i.v. LPS, the second stimulus, in normal and neutropenic guinea pigs, and found that neutrophil depletion did not attenuate LPSinduced ALI. The exact mechanism of this response remains unclear, however, plasma TNF levels in BCGprimed neutropenic guinea pigs were higher than those in non-primed animals, suggesting that more cytokine was released from mononuclear cells and caused ALI. Increased TNF production in primed animals was also observed in the BALF and plasma of the i.t. LPSinduced guinea pigs. ${ }^{53}$ All this data would imply the nonnegligible role of mononuclear phagocytes in producing ALI.

\section{Therapeutic consideration}

Despite recent advances in the understanding of cellular and humoral mechanisms of ALI, there is no specific agent for controlling lung inflammation and permeability, clinically. Corticosteroids have been the only therapeutic option, but were proven to be ineffective in prospective multicenter trials conducted in the US. ${ }^{54}$ They do not prevent the development of ARDS, hasten its reversal, affect its fatality rate, or improve respiratory function. Furthermore, Bone et $a l^{55}$ reported that corticosteroids may be harmful to patients with elevated creatinine levels. Thus, it appears that corticosteroids should not be given to patients with ARDS, ALI, or sepsis syndrome. In actual settings of clinical practice, however, the etiologies could not be determined in many patients presenting diffuse pulmonary infiltrates and acute respiratory failure. Among these, bronchiolitis obliterance with organizing pneumonia (BOOP), acute eosinophilic pneumonia and drug-induced lung diseases are involved, and significant proportion of these patients may respond to corticosteroids. The practical implication of these instances might indicate the use of corticosteroids in patients with diffuse pulmonary infiltrates of unknown etiologies. But the diagnosis is once established as being ALI and ARDS, I believe that we should not use corticosteroids. Many other drugs believed to block or limit inflammatory cascade have been tested both experimentally and clinically. ${ }^{54,56} \mathrm{We}$ have found that some agents are effective 
in animal studies, ${ }^{57-61}$ but their clinical value remains to be seen.

The reasons for the slow progress in finding adequate pharmaceuticals to control ALI and the discrepancy between the results in human ALI and those in animal models are; 1) the clinical spectrum of ALI is poorly defined, and the central inflammatory process remains unclear, resulting in the heterogeneity of the syndrome and blurring of the target of pharmacological interventions, and 2) an adequate animal model which is more comparable to persistant human ALI is unavailable while most reported animal studies were performed in acute experiment using either one or only a few stimuli. Therapeutically speaking, we are not even sure that we could successfully manage patients with ALI if we treat them early. Past experience has demonstrated that treatment with a single agent is unlikely to change the fatality rate. Rather, successful treatment may require multiple agents to block and modulate the spectrum of the inflammatory cascade in ALI.

Further improvements in the management and care of patients with ALI and ARDS will require a better understanding of the pathogenic mechanisms leading to morbidity and mortality of this syndrome. Studying ALI includes the understanding of both the vast number of cells and their products in the lungs and their potential interactions. It is likely that many synergistic actions, like priming, are of clinical importance. The interruption of the pathogenetic sequence at multiple points is our best hope of reducing the continuing high mortality from this serious syndrome.

\section{References}

1. Murray JF, Matthay MA, Luce JM, Flick MR: An expanded definition of the adult respiratory distress syndrome. Am Rev Respir Dis 1988; 138: 720-723

2. Bernard GR, Artigas A, Brigham KL, Carlet J, Falke K, Hudson L, Lamy M, Legall JR, Morris A, Spragg R: The AmericanEuropean Consensus Conference on ARDS. Definitions, mechanisms, relevant outcomes, and clinical trial coordination. Am J Respir Crit Care Med 1994; 149: 818-824

3. Ashbaugh DG, Bigelow DB, Petty TL, Levine BE: Acute respiratory distress in adults. Lancet $1967 ; 2: 319-323$

4. Bone RC, Balk RA, Cerra FB, Dellinger RP, Fein AM, Knaus WA, Schein RM, Sibbald WJ: Definitions for sepsis and organ failure and guidelines for the use of innovative therapies in sepsis. The ACCP/SCCM Consensus Conference Committee. Chest 1992; 11: $575-580$

5. Rangel-Frausto MS, Pittet D, Costigan M, Hwang T, Davis CD, Wenzel RP: The natural history of the systemic inflammatory response syndrome (SIRS). JAMA 1995; 273: 117-123

6. Sakamaki $F$, Ishizaka A, Hasegawa N, Urano $T$, Sayama $K$, Nakamura H, Terashima T, Waki Y, Tasaka S, Fujishima S, Kanazawa M, Kawashiro T: Clinical significance of measuring myeloperoxidase, thiobarbituric acid reactive material and $7 \mathrm{~S}$ collagen in plasma of patients with adult respiratory distress syndrome. Intern Med 1994; 33: 257-262
7. Sakamaki F, Ishizaka A, Handa M, Fujishima S, Urano T, Sayama K, Nakamura H, Kanazawa M, Kawashiro T, Katayama M, Ikeda Y: Soluble form of P-selectin in plasma is elevated in acute lung injury. Am J Respir Crit Care Med 1995; 151: 18211826

8. Kanazawa M, Nakamura M, Matsubara H, Sakamaki F, Fujishima S, Ishizaka A: Pathophysiology and diagnosis of acute respiratory distress syndrome. Proceedings of Symposium on "Acute lung injury", the 35th Annual Meeting of Japanese Thoracic Society 1995. Nippon Kyobu Shikkan Gakkai Zasshi (Jpn J Thorac Dis) 1995; 33S: 245-250 (in Japanese)

9. Montgomery AB, Stager MA, Carrico J, Hudson LD: Causes of mortality in patients with the adult respiratury distress syndrome. Am Rev Respir Dis 1985; 132: 485-489

10. Murray JF, The Staff of the Division of Lung Diseases, National Heart, Lung, and Blood Institute: Conference report: mechanisms of acute respiratory failure. Am Rev Respir Dis 1977; 115: 10711078

11. Villar J, Slutsky AS: The incidence of the adult respiratory distress syndrome. Am Rev Respir Dis 1989; 140: 814-816

12. Webster NR, Cohen AT, Nunn JF: Adult respiratory distress syndrome - how many cases in the UK? Anaesthesia 1988; 43: 923-926

13. Dorinsky PM, Gadek JE: Multiple organ failure. Clin Chest Med 1990; 11: 581-591

14. Milberg JA, Davis DR, Steinberg KP. Hudson LD: Improved survival of patients with acute respiratory distress syndrome (ARDS): 1983-1993. JAMA 1995; 273: 306-309

15. Staub NC, Hyde RW, Crandall E: Workshop on techniques to evaluate lung alveolar - microvascular injury. Am Rev Respir Dis 1990; 141: $1071-1077$

16. Kanazawa M, Hussein A, van Schaick S, Loyd J, Scott M, Lee GJ: Noninvasive measurement of regional lung water distribution in healthy man and in pulmonary oedema. Bull Eur Physiopathol Respir 1987; 23: 359-368

17. Kanazawa M, Suzuki $Y$, Ishizaka A, Yokoyama $T$ : Comparison of two tracer kinetic methods to estimate permeability of pulmonary epithelium and capillary endothelium in man. In: Ueda G et al, eds, High-altitude Medical Science: Proceedings of Matsumoto International Symposium on High-altitude Medical Science, Matsumoto, Japan, Shinshu University, 1988; 156-160

18. Kanazawa M: Estimation of lung volume and pulmonary blood volume from radioisotopic images change. Nippon Kyoubu Shikkan Gakkai Zasshi (Jpn J Thorac Dis) 1989; 27: 263-266 (in Japanese)

19. O'Brodovich H, Coates G: Pulmonary clearance of ${ }^{99_{\mathrm{m}}} \mathrm{Tc}$-DTPA: a noninvasive assessment of epithelial integrity. Lung 1987; 165 : $1-16$

20. Suzuki Y, Kanazawa M, Fujishima S, Ishizaka A, Kubo A: Effect of external negative pressure on pulmonary ${ }^{99 \mathrm{~m}} \mathrm{Tc}$-DTPA clearance in humans. Am J Respir Crit Care Med 1995; 152: 108-112

21. Ishizaka A, Kanazawa M, Suzuki Y, Hasegawa N, Kubo A, Kawashiro T: Influence of chest background on pulmonary ${ }^{99 \mathrm{~m}} \mathrm{Tc}-$ DTPA clearance in interstitial lung disease. J Appl Physiol 1992; 73: $1820-1824$

22. Braude S, Nolop KB, Hughes JM, Barnes PJ, Royston D: Comparison of lung vascular and epithelial permeability indices in the adult respiratory distress syndrome. Am Rev Respir Dis 1986; 133: 1002-1005

23. Tasaka S, Waki Y, Ishizaka A, Aoki T, Urano T, Sayama K, Sakamaki F, Nakamura H, Terashima T, Kanazawa M, Kawashiro $\mathrm{T}$ : Changes in pulmonary epithelial permeability during hyperoxia measured by pulmonary clearance of ${ }^{99 \mathrm{~m}} \mathrm{Tc}$-dialdehyde starch in guinea pig. Am Rev Respir Dis 1993; 147: A922

24. Gorin AB, Weidner WJ, Demling RH, Staub NC: Noninvasive measurement of pulmonary transvascular protein flux in sheep. 
J Appl Physiol 1978; 45: 225-233

25. Nakamura $H$, Ishizaka A, Sawafuji M, Urano T, Fujishima $S$, Sakamaki F, Sayama K, Kawamura M, Kato R, Kikuchi K, Kanazawa M, Kobayashi K, Kawashiro T: Elevated levels of interleukin-8 and leukotriene B4 in pulmonary edema fluid of a patient with reexpansion pulmonary edema. Am J Respir Crit Care Med 1994; 149: 1037-1040

26. Hammerschmidt DE, Weaver LJ, Hudson LD, Craddock PR, Jacob HS: Association of complement activation and elevated plasma $\mathrm{C} 5$ a with adult respiratory distress syndrome. Pathophysiological relevance and possible prognostic value. Lancet 1980; 1 : 947-949

27. Weinberg PF, Matthay MA, Webster RO, Roskos KV, Goldstein IM, Murray JF: Biologically active products of complement and acute lung injury in patients with the sepsis syndrome. Am Rev Respir Dis 1984; 130: 791-796

28. Rinaldo JE: Mediation of ARDS by leukocytes. Clinical evidence and implications for therapy. Chest 1986; 89: 590-593

29. Fujishima S, Sasaki J, Shinozawa Y, Takuma K, Hori S, Aikawa $\mathrm{N}$ : Interleukin 8 in ARDS. Lancet 1993; 342: 237-238

30. Matsubara H, Fujishima S, Sayama K, Akasaka Y, Yamasawa F, Ishizaka A, Yamaguchi K. Kanazawa M: Chronological observation of Interleukin-8 in bronchoalveolar lavage fluid in a patient with adult respiratory distress syndrome. Nippon Kyobu Shikkan Gakkai Zasshi (Jpn J Thorac Dis) 1996; 34: 552-556 (in Japanese)

31. Ishizaka A, Stephens KE, Tazelaar HD, Hall EW, O'Hanley P, Raffin TA: Pulmonary edema after Escherichia coli peritonitis correlates with thiobarbituric-acid - reactive materials in bronchoalveolar lavage fluid. Am Rev Respir Dis 1988; 137: 783-789

32. Kawamura M, Yamasawa F, Ishizaka A, Kato R, Kikuchi $K$, Kobayashi K, Aoki T, Sakamaki F, Hasegawa N, Kawashiro T, Ishihara $\mathrm{T}$ : Serum concentration of $7 \mathrm{~S}$ collagen and prognosis in patients with the adult respiratory distress syndrome. Thorax 1994; 49: 144-146

33. Katayama M, Handa M, Araki Y, Ambo Y, Kawai Y, Watanabe $\mathrm{K}$, Ikeda $\mathrm{Y}$ : Soluble P-selectin is present in normal circulation and its plasma level is elevated in patients with thrombotic thrombocytopenic purpura and hemolytic uremic syndrome. $\mathrm{Br} \mathrm{J}$ Haematol 1993; 84: 702-710

34. Rinaldo JE, Rogers RM: Adult respiratory distress syndrome: changing concepts of lung injury and repair. N Engl J Med 1982; 306: $900-909$

35. Tate RM, Repine JE: Neutrophils and the adult respiratory distress syndrome. Am Rev Respir Dis 1983; 128: 552-559

36. Weiss SJ: Tissue destruction by neutrophils. N Engl J Med 1989; 320: $365-376$

37. Heflin AC Jr, Brigham KL: Prevention by granulocyte depletion of increased vascular permeability of sheep lung following endotoxemia. J Clin Invest 1981; 68: 1253-1260

38. Glauser FL, Fairman RP: The uncertain role of the ncutrophil in increased permeability pulmonary edema. Chest 1985; 88: 601607

39. Kanazawa M, Ishizaka A, Hasegawa N, Suzuki Y, Yokoyama T: Granulocyte colony-stimulating factor does not cnhance endotoxininduced acute lung injury in guinea pigs. Am Rev Respir Dis 1992; 145: 1030-1035

40. Stephens KE, Ishizaka A, Wu ZH, Larrick JW, Raffin TA: Granulocyte depletion prevents tumor necrosis factor-mediated acute lung injury in guinea pigs. Am Rev Respir Dis 1988; 138: $1300-1307$

41. Terashima $T$, Kanazawa $M$, Sayama $K$, Ishizaka A, Urano $T$, Sakamaki F, Nakamura H, Waki Y, Tasaka S: Granulocyte colony-stimulating factor exacerbates acute lung injury induced by intratracheal endotoxin in guinea pigs. Am J Respir Crit Care Med 1994: 149: 1295-1303

42. Terashima T, Kanazawa M, Sayama K, Urano T, Sakamaki
F, Nakamura H, Waki Y, Soejima K, Tasaka S, Ishizaka A: Neutrophil-induced lung protection and injury are dependent on the amount of pseudomonas aeruginosa administered via airways in guinea pigs. Am J Respir Crit Care Med 1995; 152: 2150-2156

43. Terashima T, Soejima K, Waki Y, Nakamura H, Fujishima S, Suzuki $Y$, Ishizaka A, Kanazawa M: Neutrophils activated by granulocyte colony-stimulating factor suppress tumor necrosis factor-a release from monocytes stimulated by endotoxin. Am J Respir Cell Mol Biol 1995; 13: 69-73

44. Ognibene FP, Martin SE, Parker MM, Schlesinger T, Roach P, Burch C, Shelharmer JH, Parrillo JE: Adult respiratory distress synorome in patients with severe neutropenia. $N$ Engl J Med 1986; 315: 547-551

45. Sibille Y, Reynolds HY: Macrophages and polymorphonuclear neutrophils in lung defense and injury. Am Rev Respir Dis 1990; $141 ; 471-501$

46. McGowan SE, Stone PJ, Snider GL, Franzblau C: Alveolar macrophage modulation of proteolysis by neutrophil elastase in extracellular matrix. Am Rev Respir Dis 1984; 130: 734-739

47. Nelson S, Bagby GJ, Bainton BG, Wilson LA, Thompson JJ, Summer WR: Compartmentalization of intraalveolar and systemic lipopolysaccharide-induced tumor necrosis factor and the pulmonary inflammatory response. J Infect Dis 1989; 159: 189-194

48. Terashima T, Matsubara H, Nakamura M, Sakamaki F, Waki Y, Soejima K, Tasaka S, Nakamura H, Sayama K, Ishizaka A, Kanazawa M: Local pseudomonas aeruginosa aspiration induces acute lung injury in non-aspirated region associated with systemic cytokine release. Am J Respir Crit Care Med 1996; 153: 16001605

49. Tutor JD, Mason CM, Dobard E, Beckerman RC, Summer WR, Nelson S: Loss of compartmentalization of alveolar tumor necrosis factor after lung injury. Am J Respir Crit Care Med 1994; 149: $1107-1111$

50. Ishizaka A, Hasegawa $N$, Sayama $K$, Urano $T$, Nakamura $H$, Sakamaki F, Soejima K, Waki Y, Tasaka S, Nakamura M, Matsubara H, Kanazawa M: Augmentation of endotoxin induced pulmonary responses by mononuclear cell phagocytosis in reticuloendothelial system. Crit Care Med 1996; 24: 1034-1040

51. Nakamura H, Fujishima S, Waki Y, Urano T, Sayama K, Sakamaki F, Terashima $T$, Soejima K, Tasaka S, Ishizaka A, Kawashiro T, Kanazawa M: Priming of alveolar macrophages for interleukin-8 production in patients with idiopathic pulmonary fibrosis. Am J Respir Crit Care Med 1995; 152: 1579-1586

52. Tasaka S, Ishizaka A, Urano T, Sayama K, Sakamaki F, Nakamura H, Terashima T, Waki Y, Soejima K, Oyamada Y, Fujishima S, Kanazawa M: BCG priming enhances endotoxin-induced acute lung injury independent of neutrophils. Am J Respir Crit Care Med 1995; 152: 1041-1049

53. Tasaka S, Ishizaka A, Sayama K, Sakamaki F, Nakamura $\mathbf{H}$, Terashima T, Waki Y, Soejima K, Nakamura M, Matsubara H, Fujishima S, Kanazawa M: Heat-killed corynebacterium parvum enhances endotoxin lung injury with increased TNF production in guinea pigs. Am J Respir Crit Care Med 1996; 153: 1047-1055

54. Goldstein G, Luce JM: Pharmacologic treatment of the adult respiratory distress syndrome. Clin Chest Med 1990; 11: 773-787

55. Bone RC, Fisher CJ Jr, Clemmer TP, Slotman GJ, Metz CA, Balk RA: A controlled clinical trial of high-dose methylprednisolone in the treatment of severe sepsis and septic shock. N Engl J Med 1987; 317: 653-658

56. Said SI, Foda HD: Pharmacologic modulation of lung injury. Am Rev Respir Dis 1989; 139: 1553-1564

57. Ishizaka A, Hasegawa N, Sakamaki F, Tasaka S, Nakamura H, Kishikawa K, Yamada A, Obata T, Sayama K, Urano T, Kanazawa M: Effects of ONO-1078, a peptide leukotriene antagonist, on endotoxin-induced acute lung injury. Am J Respir Crit Care Med 1994: 150: $1325-1331$ 
58. Sakamaki F, Ishizaka A, Urano T, Sayama $K$, Nakamura $H$, Terashima T, Waki Y, Tasaka S, Hasegawa N, Sato K, Nakagawa N, Obata T, Kanazawa M: The effect of a specific neutrophil elastase inhibitor, ONO-5046, on endotoxin induced acute lung injury. Am J Respir Crit Care Med 1996; 153: 391-397

59. Nakamura H, Ishizaka A, Urano T, Sayama K, Sakamaki F, Terashima T, Waki $Y$, Soejima $K$, Tasaka S, Hasegawa $N$, Fujishima S, Kanazawa M: Effects of pretreatment with SDZ MRL 953, a novel immunostimulatory lipid A analog, on endotoxininduced acute lung injury in guinea pigs. Clin Diag Lab Immun $1995 ; 2: 672-677$
60. Soejima $K$, Ishizaka A, Urano T, Sayama K, Sakamaki F, Nakamura H, Terashima T, Waki Y, Tasaka S, Fujishima S, Kawata T, Christ JW, Kanazawa M: Protective effect of B464, a lipid $\mathrm{A}$ analog, on endotoxin-induced cellular responses in vitro and acute lung injury in vivo. Am J Respir Crit Care Med (in press)

61. Tasaka S, Ishizaka A, Urano T, Sayama K, Sakamaki F, Nakamura H, Terashima T, Waki Y, Soejima K, Fujishima S, Kanazawa M: Attenuation of hyperoxic lung injury by the 21-aminosteroid U-74389G. J Appl Physiol 1995; 78: 1635-1641 